\title{
Educación y alteridad. Las figuras del extranjero.
}

FRIGERIO, Gabriela; DIKER, Gabriela (Comp.). Educación y alteridad. Las figuras del extranjero. Textos multidisciplinarios. Buenos Aires: Novedades Educativas - fundación CEM, 2003.

(Colección ensayos y experiencias, $n^{\circ} 48$ )

Reseñado por: Mariana Alvarado(1)

Las figuras del extranjero que fueron albergadas en el debate propiciado por el Centro de Estudios Multidisciplinarios (CEM) en noviembre de 2002 al momento pueden ser abordadas en la revista que difunde dieciséis trabajos bajo el título Educación y alteridad.

La densidad semántica de la categoría de "lo extranjero" proyecta una multiplicidad simbólica capaz de ser acometida desde diferentes líneas de análisis que convergen en una intención que subyace a los trabajos que aquí tenemos por intención reseñar: desbordar sus sentidos en lo dicho, en lo no dicho y en lo aún por decir; descentrar de las prácticas los discursos que institucionalizan formas de mirar al otro; destronar la hegemonía de un relato que excluye cuando nos dice la verdad de lo que somos; oxigenar desde la multiplicidad analítica los escenarios en los que se construyen sujetos a la vez que se borran y profundizan las diferencias; acoger la posibilidad de que la educación y la escuela sean situadas en un tiempo en el que la ética de la alteridad tenga la posibilidad de recrear las coordenadas en el periplo que acontece en el encuentro con el otro.

Los conceptos se articulan en el tiempo de un viaje en el que los adioses y las despedidas abrazan una partida con forma de exilio para la cual caben las formas del anfitrión y el huesped, del familiar y el extranjero, que pueden indistintamente pasar a ser el intruso y, por qué no, el rehén en un lugar tal como el hogar y/o el hospedaje, el hotel o el cementerio. Una vía, la discursiva, es el camino por el que cada uno de los autores transita una forma de atender los múltiples motivos por los que un sujeto se vuelve peregrino de una travesía que puede bien transcurrir sin desplazamiento geográfico. Este es el horizonte desde el cual Graciela Frigerio abre la reflexión sobre Las figuras del extranjero y algunas de sus resonancias para luego, extenderse sobre las relaciones pedagógicas en las que el extranjero es el profesor para el alumno, el alumno para el profesor, el conocimiento para el que desea saber.

La institución educativa en cuanto tiene a su cargo la función de gestionar la construcción de la subjetividad es la encargada de reproducir la humanidad desde la fabricación del semejante. Esta es la idea eje que atraviesa los trabajos de Andrea Berenblum, Margarita Poggi, Gabriela Diker, Gladys Kochen, Estanislao Antelo, Silvia Alderoqui y Silvia Serra.

Beremblum, en el artículo "Lengua, identidad nacional y prácticas educacionales" (p 84 - 91), sitúa la construcción de la identidad como instancia en la que intervienen procesos ligados al campo de lenguaje para reflexionar acerca del modo en el que lo hablado, lo escrito y lo pensado definen una lengua ajena y una 
lengua propia, extranjera o nacional al tiempo que recrean el sentimiento de pertenencia y el de extranjería. La autora repasa sus experiencias doctorales en Brasil - cuya tesis llevó por título "La invención de la palabra oficial. Identidad y lengua nacional en tiempos de globalización" - para tomar como punto de partida una vivencia: el acento como marca de la diferencia entre los cariocas y la porteña, argentina, como instancia desde la cual es posible reconocer a los sujetos naturales en una ciudad de aquellos otros que no lo son.

Margarita Poggi, en "Algunos aportes conceptuales para abordar la pluralidad, la igualdad y la diversidad en educación" (p 92 - 99), se mantiene en los márgenes teóricos del universalismo y del relativismo para abordar la inconmensurabilidad cultural desde las nociones de pluralismo y multiculturalismo. Lo diverso se hace manifiesto en parejas conceptuales tales como "nosotros y los otros", "alteridad e identidad", "civilizado y bárbaro", "familiar y extraño", "conocido y desconocido". Articular nuevas relaciones desde donde puedan ser abordados cada uno de los territorios que cada par de términos tiende entre la escuela y sus actores es la intención que puede ser sintetizada en la pregunta ¿̇cuáles son las condiciones y límites que caracterizan una escuela en la que el reconocimiento de la diferencia puede conducir a la renuncia de principios universales?.

La figura del extranjero es la metáfora que le permite a Gabriela Diker, bajo el título "Nativos, extranjeros y exiliados del territorio de la pedagogía" (p. 100 - 109), reflexionar acerca de las transformaciones operadas entre los profesores y maestros con la producción escrita de un saber teórico y práctico que establece qué sujetos, qué objetos, qué reglas y qué instituciones están dentro o fuera de la pedagogía y que por la restricción del espacio en el que circula, por las temáticas sobre las que profiere la palabra, por el formato de los textos que produce, por las modalidades que implementa, está autorizado por la institución educativa.

La escuela que ha tenido por función la homogeneización de las diferencias en la integración se nos presenta hoy, para los niños y, según Gladys Kochen, como la agenciadora de segmentación y exclusión entre los que están dentro y los que están fuera de ella. "La escuela y la inclusión del otro" (p. 110 - 117), es la línea de análisis que señala al abandono, la deserción y la repitencia como hechos que acusan de excluyente a una institución que se dice, por ley y en apariencia, inclusiva. La autora reflexiona acerca de los modos y los lugares en los que el que está del otro lado, permanece excluido de la infancia pero incluido en la vida política y social.

Dar y abordar son las acciones centrales en la práctica educativa áulica desde la que el enseñante es el intérprete que da inicio a un viaje en el que no está solo porque se dirige a un alguien con otra lengua que la propia, para hablar de otro mundo que el propio y en un lugar que no es el familiar. Antelo -"Maestros poliglotas: cuando educar es tener con quién hablar" (p 118-126) - resignifica desde la jerga estudiantil a la educación como un hacer que se comparte con otros a condición de tener cierto talento para parlotear varias lenguas. Políglotas y aspirantes mediados por el desconocimiento condición de acceso a una relación que puede fijar el destino entre lo enseñado y la salida de la escuela. 
Lo extranjero permanece en el anonimato de un rostro que se encarna en múltiples nombres que definen al otro asignándole un lugar, un rol y una forma de relacionarse con lo igual. Héléne Védrine (p. 24-33) sitúa en el Renacimiento al tiempo en el que la extranjeridad es el instrumento de una teoría teológica-política de la exclusión que sitúa a la tolerancia como problemática desde la cual se asimila o se diferencia a la otredad desde la unidad del género humano. Susana Villavicencio -"Las figuras del extranjero en la construcción de ciudadanía en la Argentina" (p. 64 - 73)- hace historia en la construcción político jurídica que postula la ciudadanía argentina al tiempo que define un proyecto de país en las fórmulas de Sarmiento y Alberdi opuesto al que más tarde formulará Ingenieros. La autora evidencia el desplazamiento en la concepción del extranjero desde las construcciones ideológicas identitarias mencionadas precedentemente.

Del cuerpo extraño al cuerpo viviente, desde la intrusa exterioridad a la amenaza interna del organismo. Laurence Cornu -"El cuerpo extranjero" (p 34 - 44)- atiende a descripciones biomédicas para yuxtaponerlas a un término que es socio y geopolítico: el cuerpo deja de ser sano o enfermo para adquirir la condición de social o político. De la materialidad de la carne y los huesos a la certeza de la ciencia. El mundo se ha vuelto extraño para una racionalidad que ya no puede pensarlo en los términos en los que venía haciéndolo. Según Violeta Guyot "Conceptos extranjeros, campos de conocimiento y complejidad" (p. 144 - 155)-, es preciso atender a diversos marcos teóricos que permitan apropiarse de conceptos extranjeros desterrados de la tradición para volverlos ciudadanos en los campos discursivos construidos por la ciencia actual. "Incertidumbre", "azar", "caos", "complejidad"... eran términos exiliados de la racionalidad científica pero que ahora se vuelven precisos para pensar la vertiginosidad de las transformaciones en la naturaleza, la sociedad, la cultura y los sujetos. Tales categorías son presentadas por la autora como los modelos que describen, explican y afrontan los desafíos de lo incierto en el tránsito crítico que la ciencia actual atraviesa al forjar un nuevo diálogo con aquello sobre lo que tienta versar.

Las figuras del extranjero aparecen bajo uno de sus rostros el de la alteridad atravesada por las dimensiones de lo educativo, de lo político, de lo sociológico, de lo histórico pero hechas cuerpos teóricos en la construcción que de estos constructos hacemos. Estos textos configuran un conjunto de voces que vienen a describir y explicar, interrogar y problematizar, señalar y denunciar, sospechar y criticar el movimiento que atraviesa lo propio y lo extraño, lo uno y lo múltiple, en lo que pensamos, en lo que decimos y en lo que practicamos.

(1) Prof. en filosofía. Universidad Congreso. Mendoza. Argentina. Dirección electrónica: alvaradom@uncongreso.edu.ar 